\title{
Energy-harvesting enhancement in composites of microwave-exfoliated KNN and multiwall carbon nanotubes
}

\author{
NANDINI R NADAR ${ }^{1}$, M KRISHNA ${ }^{2, *}$ and A V SURESH ${ }^{1}$ \\ ${ }^{1}$ Department of Mechanical Engineering, BMS Institute of Technology and Management, Bangalore 560064, India \\ ${ }^{2}$ Research and Development Centre, Department of Mechanical Engineering, R.V. College of Engineering, \\ Bangalore 560059, India \\ *Author for correspondence (krishnam@ rvce.edu.in)
}

MS received 25 May 2018; accepted 1 June 2019

\begin{abstract}
The objective of this research work is to investigate the effect of multiwall carbon nanotube (MWCNT) content $(0.3-1.2 \mathrm{wt} \%)$ on a potassium sodium niobate $(\mathrm{KNN})$-based piezoelectric unimorph harvester for enhancing the energy generation capacity. KNN-MWCNT composites were fabricated by using a microwave solid state technique. The energyharvesting performance of the KNN-MWCNT composite was determined by the base excitation method and sized to resonate between 20 and $100 \mathrm{~Hz}$ at $1 \mathrm{M} \Omega$ load resistance. The energy performance of the KNN composite at percolation threshold $(0.6 \mathrm{wt} \% \mathrm{MWCNT})$ showed a maximum power generation of $2.94 \mu \mathrm{W}$, the power density of $7.15 \mu \mathrm{W} \mathrm{m}^{-3}$ and overall efficiency of $83.75 \%$ at an input acceleration of $0.5 \mathrm{~g}$ and a load resistance of $1 \mathrm{M} \Omega$. Improvements observed in the power generation by percolation phenomena and ionic flow over the nanotube surface of KNN composites prove to be a boon for low-power sensing devices.
\end{abstract}

Keywords. MWCNT; KNN; KNN-MWCNT harvesters; damping; energy conversion; power density.

\section{Introduction}

The limited operating life of batteries has made energy harvesting an essential requirement for powering remote sensors. Piezoelectric transducers have attracted the attention of researchers for energy harvesting due to their remarkable energy conversion efficiency and high-specific energy density [1]. They are slowly replacing conventional power sources in low-power applications like portable electronic devices, wireless sensors and health monitoring and control systems [2,3]. It also possesses market intrusion in remote operating devices, such as transducers [4,5], sensors [6,7], actuators [8,9], surface acoustic wave devices [10,11] and frequency control [2].

The piezoelectric energy harvester's capacity can be tailored by its functional properties, such as electromechanical coupling coefficients, piezoelectric strain coefficients, dielectric constant, density and electrical and mechanical quality factors. The major share of piezoelectric energy-harvesting market is captured by lead-based piezoelectric materials like lead zirconate titanate (PZT) due to their excellent performance [12-15]. The presence of $60 \%$ lead by weight in PZT is extremely toxic to the environment and human beings. In this regard, 'The restriction of hazardous substances directive' legislation was passed by the European Union in 2003 and exemption of its usage ends by 2016 [16]. Leadfree-based potassium sodium niobate $(\mathrm{KNN})$ ceramics have revolutionized the piezoelectric industry for energy harvesting. It is mainly because of their high-Curie temperature and the presence of a morphotropic phase boundary between two-orthorhombic phases [17,18]. KNN finds numerous practical applications, such as electronic transducers [19], voltage transformers [20], multilayer actuators [21] and ultrasonic motors [22]. Alkaline $\left(\mathrm{Li}^{+}, \mathrm{Ba}^{2+}, \mathrm{La}^{3+}, \mathrm{Bi}^{3+}\right)$ and transition $\left(\mathrm{Ti}^{4+}, \mathrm{Sb}^{5+}, \mathrm{Ta}^{5+}\right)$ element-doped $\mathrm{KNN}$ ceramics were developed to enhance the functional properties and thermal stability by shifting the polymorphic phase transition (PPT) [23-26]. Even though modified-KNN ceramics have captured the piezoelectric market for buzzers (lithium and Sb-doped $\mathrm{KNN})$ [27] and actuators (K, Na, Li, Ba, Sr) (Nb, Ta, Zr) $\mathrm{O}_{3}$ ceramic [28] applications, sensitive processing issues, temperature-dependent piezoelectric properties and poor stability of the poled domain state provide further scope for improvements $[26,29,30]$ in KNN ceramics for electronics and energy-harvesting applications.

Carbon nanotube (CNT) reinforced polymer compositebased piezoelectric materials show remarkable enhancement in the stability of the poled domain state and improvement in processing sensitivity and thermal stability [31-34]. An increase of $61.3 \%$ in piezoelectric charge coefficient $(19.8 \mathrm{pC} / \mathrm{N}), 67 \%$ increase in dielectric constant, $89 \%$ increase in dielectric loss factor, significant elastic moduli with a good frequency and energy conversion response were reported for CNT reinforced PZT-PVA 0-3 and CNT-PZT epoxy matrix composites [31-34]. Even though the CNT is a potential candidate for tailoring the functional properties of piezoelectric ceramics, no research studies have focussed on 
developing CNT reinforced KNN-based piezoelectric energy harvesters (PEHs). The objective of the present research work was to develop and evaluate the energy conversion performance of a KNN-MWCNT (0.3-0.9 wt\%)-based piezoelectric harvester. The developed piezoelectric harvesters were subjected to sinusoidal vibrations using a shaker in transverse mode by using the base excitation method at an input acceleration of $0.5 \mathrm{~g}$, between 20 and $100 \mathrm{~Hz}$ for evaluating the energy performance of KNN composite-based harvesters.

\section{Materials and methods}

The stoichiometric computation of elemental powders, i.e., $\mathrm{Na}_{2} \mathrm{CO}_{3}, \mathrm{~K}_{2} \mathrm{CO}_{3}$ and $\mathrm{Nb}_{2} \mathrm{O}_{5}$ of $35 \mathrm{~g}$ were preheated at $200^{\circ} \mathrm{C}$ for $2 \mathrm{~h}$ and were ball milled for $15 \mathrm{~h}$ at $300 \mathrm{rpm}$ with a ball-to-powder ratio of 10:1 to obtain homogenously milled $\left(\mathrm{K}_{0.5} \mathrm{Na}_{0.5}\right)-\mathrm{NbO}_{3}$ nanopowder. The blended $\mathrm{KNN}$ powder was calcined at $900^{\circ} \mathrm{C}$ for $5 \mathrm{~h}$ and remilled for $2 \mathrm{~h}$ to obtain non-agglomerated KNN nanopowder. Functionalized, surface treated and ultrasonicated MWCNTs $(0.3-1.2 \mathrm{wt} \%)$ were mixed with a known mass of KNN slurry in ethanol medium and sonicated for $2 \mathrm{~h}$ to obtain a uniform dispersion [35]. Then vacuum dried KNN-MWCNT composite powder was pressed uniaxially at $250 \mathrm{MPa}$ for preparing discs with a diameter of $10 \mathrm{~mm}$ and a thickness of $1.5 \mathrm{~mm}$. The green compacts of KNN composites were densified by microwave-assisted sintering at $1100^{\circ} \mathrm{C}$ for $30 \mathrm{~min}$. The obtained $\mathrm{KNN}$ composite discs were polished by using silicon carbide powder and were coated with silver paste on both parallel surfaces for electrical measurements. For piezoelectric activation, all samples were polled in a silicon oil bath under a poling field of $2.5-4 \mathrm{kV}$ $\mathrm{mm}^{-1} \mathrm{dc}$ for $30 \mathrm{~min}$ at an optimized temperature using the parallel plate contact polarization method and a Spellman SL Series high-voltage generator [35]. The strain induced in the KNN lattice due to the presence of MWCNTs was measured using a precision premier II ferroelectric tester (Radiant technologies.INC) to evaluate high-energy dissipating multiwall type failures and plastic buckling as reported in our previous research article [35]. It is simultaneously responsible for strengthening, toughening and softening of the matrix along strain induction in the KNN lattice.

The poled KNN-MWCNT (0.3-1.2 wt\%) composites with a diameter of $10 \mathrm{~mm}$ and a thickness of $1.3 \mathrm{~mm}$ were attached to a steel cantilever beam of dimension $88 \mathrm{~mm} \times 12 \mathrm{~mm}$ $\times 0.3 \mathrm{~mm}$ using silver epoxy and were cured for $12 \mathrm{~h}$ to obtain appropriate adhesion between the composite disc and the beam. The copper tape was applied to the edge surface of the disc and to the steel beam of the harvester to function as top and bottom electrodes. The fabricated harvesters and schematic of the test setup are shown in figures 1 and 2, respectively. KNN-MWCNT harvesters were characterized for their energy conversion performance by subjecting to sinusoidal vibrations using a shaker (LDS, V406/8PA100E, Royston) (figure 1) at $0.5 g$ acceleration

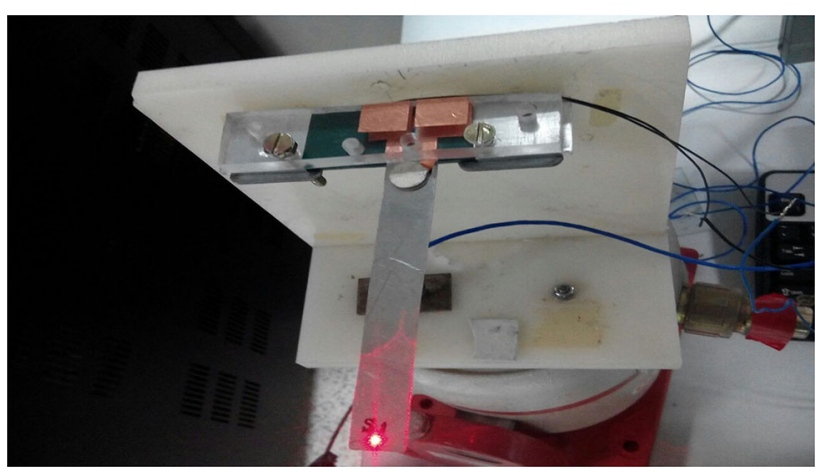

Figure 1. Fabricated KNN-MWCNT harvester subjected to a shaker tool.

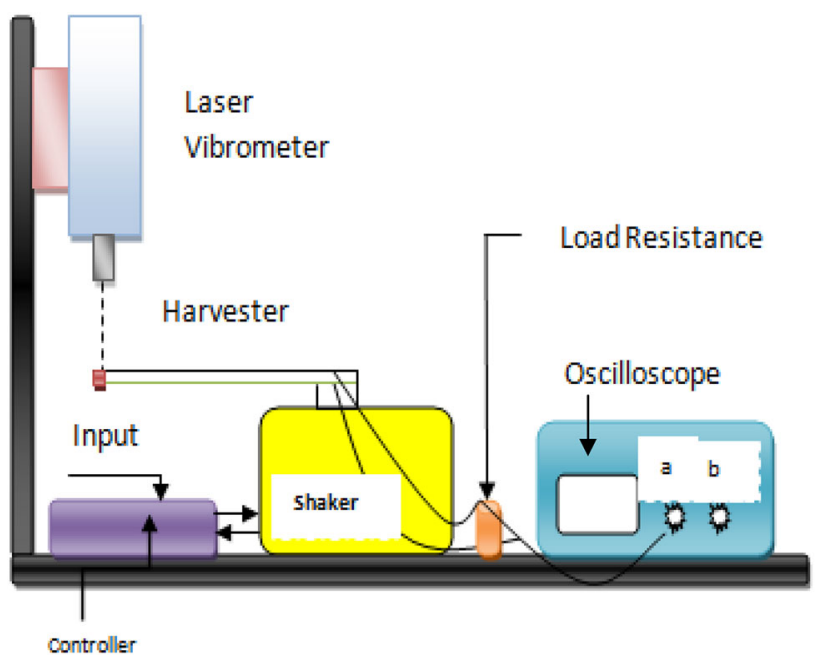

Figure 2. A schematic representation of the experimental setup to evaluate the performance of the KNN-MWCNT harvesters.

$\left(g=9.81 \mathrm{~m} \mathrm{~s}^{-2}\right)$ between 25 and $100 \mathrm{~Hz}$. The top and bottom electrodes of the harvester were linked to the load resistance and were coupled to the oscilloscope. The desired acceleration input of $0.5 \mathrm{~g}$ was assigned to the shaker by using a controller and the relative displacement of the harvesters was monitored using a laser vibrometer (Polytec-GmbH, PDV-100, Germany). The potential voltage developed in the harvester due to vibrations was measured using a Tektronix TDS1002B oscilloscope (Oregon, USA) at an optimum load resistance of $1 \mathrm{M} \Omega$ (figure 2). The damping ratio $(\xi)$ of the harvester samples was calculated through dynamic tip displacement [36]. The current flowing into the load resistance was derived from Ohm's law. The effective RMS value of the varying voltage $(\mathrm{V})$ was computed from the peak value by assuming the source to be a sine wave. The power developed at load resistance was obtained from the product of effective values of voltage and current [37] and energy conversion efficiency was evaluated by using $k_{\mathrm{p}}^{2}$ and $\zeta_{\mathrm{m}}$ values $k_{\mathrm{p}}^{2} / \zeta_{\mathrm{m}}>1$ [38]. The input power was calculated by the product of force applied (mass of the sample and input acceleration $(0.5 g)$ ) and 
displacement obtained from the harvester when subjected to base excitation. The power density was computed as the maximum output power divided by the volume of the cantilever to evaluate the power generation performance; the efficiency of the harvester was evaluated by using the output and input power parameters. Finally, the theoretical output power of the KNN-MWCNT-based piezoelectric energy-harvesting unimorph cantilever was calculated by the electric equivalent circuit model method $[39,40]$.

\section{Results}

\subsection{Effect of temperature on the conductivity of KNN composites}

The behaviour of electrical conductivity of pure KNN and its composites as a function of temperature is shown in figure 3. The conductivity in $\mathrm{KNN}$ being $4.67 \mathrm{E}^{-5} \mathrm{~S} \mathrm{~m}^{-1}$ at $22^{\circ} \mathrm{C}$ increased gradually, reached the peak at $60^{\circ} \mathrm{C}$ and decreased towards the PPT temperature at $198^{\circ} \mathrm{C}$. The conductivity of KNN-MWCNT $(0.3 \mathrm{wt} \%)$ composites as observed is $4.514 \mathrm{E}^{-5} \mathrm{~S} \mathrm{~m}^{-1}$ at $\mathrm{RT}$, was consistent up to $150^{\circ} \mathrm{C}$ and increased gradually towards PPT. The improved conductivity of $5.142 \mathrm{E}^{-5} \mathrm{~S} \mathrm{~m}^{-1}$ observed for $0.6 \mathrm{wt} \%$ loading of MWCNTs at RT was consistent with slight variation $\left( \pm 0.66 \mathrm{E}^{-5}\right)$ and increased gradually towards the PPT $\left(198^{\circ} \mathrm{C}\right)$. Furthermore, the addition of $0.9 \mathrm{wt} \%$ of MWCNT resulted in an increased conductivity of $5.54 \mathrm{E}^{-5} \mathrm{~S} \mathrm{~m}^{-1}$ at RT and obtained the maximum value of $1.16 \mathrm{E}^{-4} \mathrm{~S} \mathrm{~m}^{-1}$ towards the phase transition temperature. Finally, the addition of $1.2 \mathrm{wt} \%$ of MWCNTs into the matrix resulted with the enhanced conductance of $6.22 \mathrm{E}^{-5} \mathrm{~S} \mathrm{~m}^{-1}$ at RT but reduced drastically with an increase in temperature up to $150^{\circ} \mathrm{C}$ and increased gradually towards the phase transition temperature.

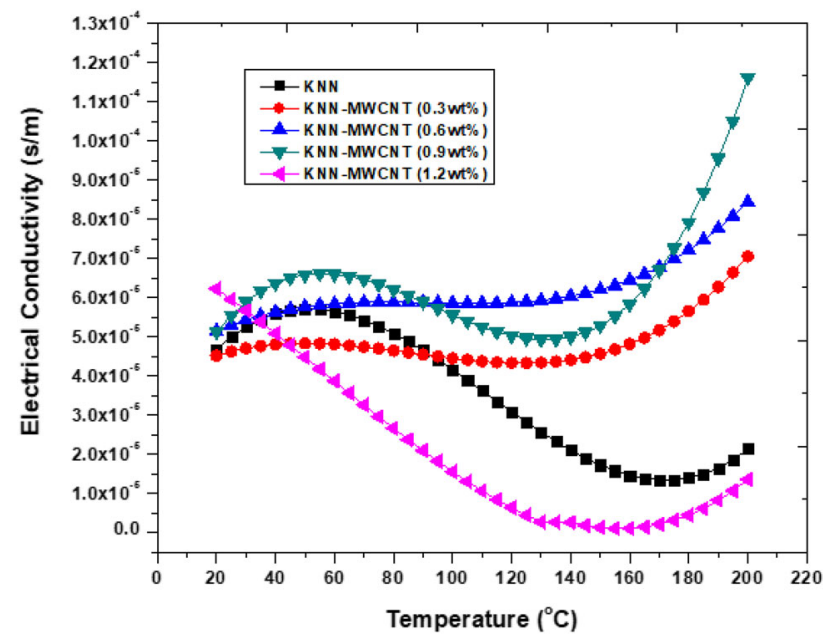

Figure 3. Temperature-dependent electrical conductivity of KNN and KNN-MWCNT composites.
Based on thermal stability, the percolation threshold for KNN composites is figured out to be $0.6 \mathrm{wt} \%$ addition of MWCNTs into the matrix.

\subsection{Displacement frequency response}

The tip displacement of the harvesters as a function of frequency for an input acceleration of $0.5 \mathrm{~g}$ is shown in figure 4 . The displacement values of all the samples measured between 10 and $50 \mathrm{~Hz}$ increased gradually with an increase in the frequency, reached maximum near its respective excitation frequency and reduced drastically thereafter as shown in figure 4. The KNN harvester measured displacement value was $1.23 \mathrm{~mm}$ at an excitation frequency of $31.22 \mathrm{~Hz}$. The addition of MWCNTs (0.3-0.9 wt\%) into the KNN matrix resulted in improvement of the displacement and excitation frequency of the KNN composite by $27.57 \%(1.25 \mathrm{~mm})$, $30.35 \%$ (1.77 mm), 9.34\% (1.34 mm), 0.70\% (31.44 Hz), $0.80 \%(31.47 \mathrm{~Hz})$ and $7.2 \%(33.47 \mathrm{~Hz})$, respectively. Further loading of MWCNTs by $1.2 \mathrm{wt} \%$ into the KNN matrix above electrical percolation resulted in a reduced displacement value of $0.49 \mathrm{~mm}$. The maximum displacement of $1.77 \mathrm{~mm}$ reported for KNN-MWCNT (0.6 wt\%) composites indicates the completion of the electroconductive network within the matrix at percolation threshold.

\subsection{Voltage-current-power frequency response}

3.3a Voltage frequency response: The voltage frequency response of KNN composite harvesters for $0.5 \mathrm{~g}$ input acceleration at a load resistance of $1 \mathrm{M} \Omega$ is shown in figure 5 . The voltage potential developed by all the samples for the given input acceleration increased gradually and attained the maximum peak for their respective excitation frequency and reduced drastically thereafter as shown in figure 5. The

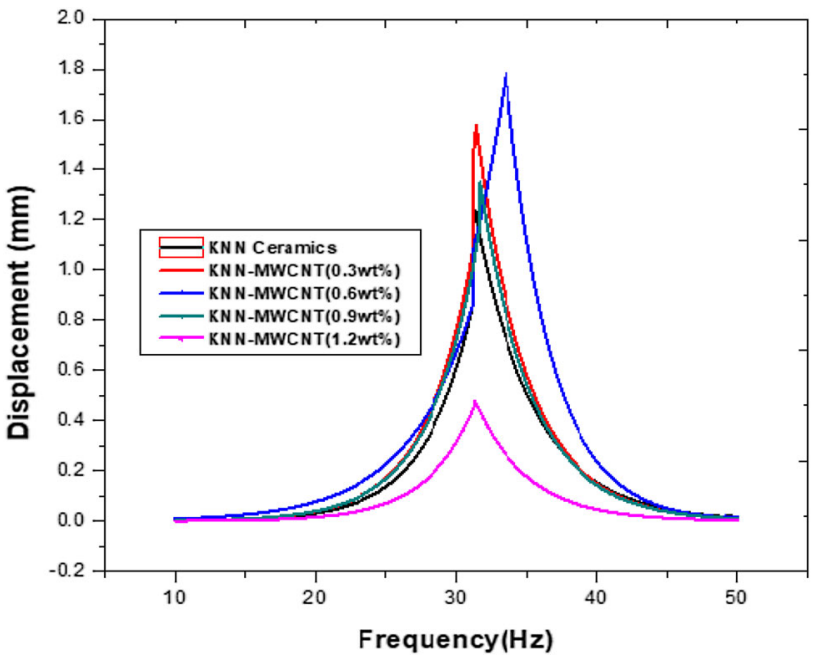

Figure 4. Displacement data of KNN harvesters extracted at a selected frequency range of $10-50 \mathrm{~Hz}$. 


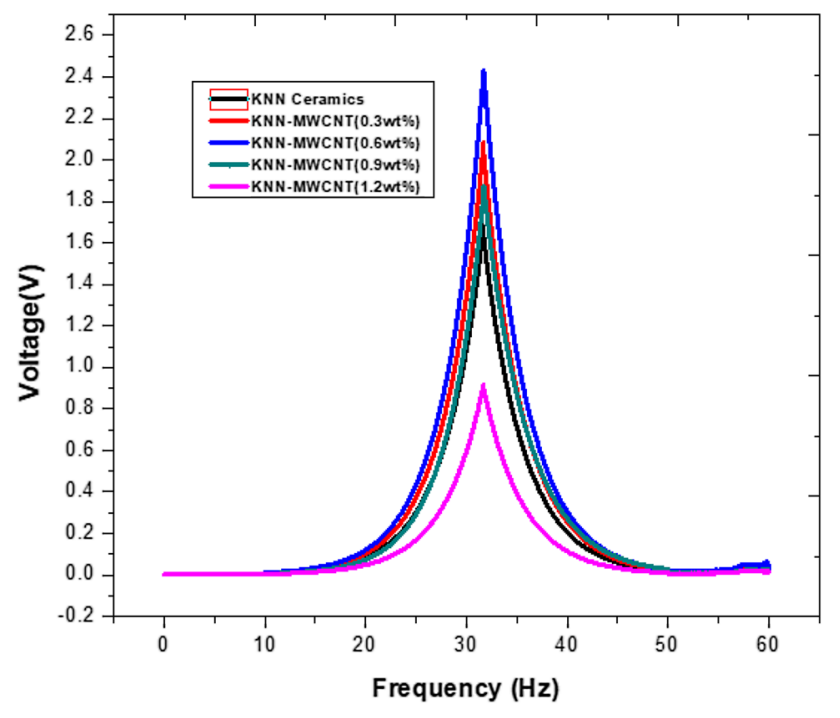

Figure 5. Voltage frequency response of KNN-MWCNT harvesters in comparison with $\mathrm{KNN}$ harvesters at an input acceleration of $0.5 \mathrm{~g}$.

voltage induced in the $\mathrm{KNN}$ harvesters due to vibrations was $1.66 \mathrm{~V}$ at an excitation frequency of $31.65 \mathrm{~Hz}$. Furthermore, the addition of MWCNTs (0.3-0.9 wt\%) into the KNN matrix resulted in the improvement of its voltage potential by $24.02 \%$ $(2.06 \mathrm{~V}$ at $31.79 \mathrm{~Hz}), 48.53 \%(2.46 \mathrm{~V}$ at $31.95 \mathrm{~Hz})$ and $12.24 \%$ $(1.86 \mathrm{~V}$ at $31.79 \mathrm{~Hz})$, respectively, with an increase in its corresponding excitation frequency. However, KNN-MWCNT composites with the concentration above the critical percolation $(1.2 \mathrm{wt} \%)$ resulted in the development of a very low potential of $0.9153 \mathrm{~V}$ in the harvester. The maximum voltage of $2.46 \mathrm{~V}$ generated in the KNN-MWCNT (0.6 wt $\%$ ) composite indicates the improved percolation path within the KNN matrix.

3.3b Current frequency response: The current frequency response of the harvesters for an input acceleration of $0.5 \mathrm{~g}$ is shown in figure 6 . The current generated by all the harvester samples increased gradually and reached a maximum at their excitation frequency and decreased further as shown in figure $6 \mathrm{a}$ and $\mathrm{b}$. It could be noticed that even the excitation frequency increased slightly with the addition of MWCNTs till $0.9 \mathrm{wt} \%$ and reduced thereafter as shown in figure $6 \mathrm{~b}$. The current generated by KNN harvesters was $1.6621 \mu \mathrm{A}$ at an excitation frequency of $31.62 \mathrm{~Hz}$. The addition of MWCNTs between 0.3 and $0.9 \mathrm{wt} \%$ into the KNN matrix enhanced the induced current by $25.30 \%(2.08 \mu \mathrm{A}$ at $31.691 \mathrm{~Hz}), 46.33 \%$ $(2.43 \mu \mathrm{A}$ at $31.75 \mathrm{~Hz})$ and $12.61 \%(1.87 \mu \mathrm{A}$ at $31.79 \mathrm{~Hz})$, respectively, with an increase in its corresponding excitation frequency. A further addition of MWCNTs by $1.2 \mathrm{wt} \%$ (above the electrical percolation) yielded only $0.9153 \mu \mathrm{A}$ at the reduced excitation frequency of $31.69 \mathrm{~Hz}$. The maximum current of $2.43 \mu \mathrm{A}$ generated in the KNN-MWCNT
(0.6 wt $\%$ )-based PEH can be attributed to the well dissipated electric energy within the composites.

3.3c Power frequency response: The power frequency response of the harvesters for an input acceleration of $0.5 \mathrm{~g}$ is shown in figure $7 \mathrm{a}$ and $\mathrm{b}$, respectively. The output power of all the harvesters increased gradually and reached a maximum at their excitation frequency and further decreased subsequently as shown in figure $7 \mathrm{~b}$. The computed output power of KNN ceramics was $1.48 \mu \mathrm{W}$ at $31.60 \mathrm{~Hz}$. The addition of MWCNTs (0.3-0.9 wt\%) into the matrix helped in the improvement of the output power by $52.20 \%(2.17 \mu \mathrm{W}$ at $31.70 \mathrm{~Hz}), 89 \%(2.97 \mu \mathrm{W}$ at $31.81 \mathrm{~Hz})$ and $24.83 \%$ $(1.78 \mu \mathrm{W}$ at $31.91 \mathrm{~Hz})$, respectively, with an increased excitation frequency due to enhanced percolation clusters and interfacial effects. However, the power generated by the addition of MWCNTs above the percolation threshold (1.2 wt\%) resulted in least output power $(0.4714 \mu \mathrm{W}$ at $31.70 \mathrm{~Hz})$ in comparison with pure KNN harvesters. This effect can be associated with reduced connectivity between the charge carriers within the matrix. It is due to the formation of agglomeration and high porosity for loading of MWCNTs above the threshold.

3.3d Power density frequency response: The harvested power density of KNN composites for loading of MWCNTs between 0.3 and $1.2 \mathrm{wt} \%$ as a function of frequency $(14-45 \mathrm{~Hz})$ is depicted in figure 8. It is observed from the graph that the amplitude of the power density for all PEHs increased gradually and reached a maximum near its respective excitation frequency and decreased sharply thereafter. The amplitude of the power density evaluated for KNN ceramics was $4.13 \mu \mathrm{W} \mathrm{m}^{-3}$ at $31.66 \mathrm{~Hz}$. The addition of MWCNTs (0.3-0.9 wt \%) into the KNN matrix enhanced the power density by $26.63 \%\left(5.23 \mu \mathrm{W} \mathrm{m}^{-3}\right.$ at $\left.31.70 \mathrm{~Hz}\right), 44.34 \%$ $\left(5.97 \mu \mathrm{W} \mathrm{m} \mathrm{m}^{-3}\right.$ at $\left.31.82 \mathrm{~Hz}\right)$ and $10.65 \%\left(4.57 \mu \mathrm{W} \mathrm{m} \mathrm{m}^{-3}\right.$ at $31.91 \mathrm{~Hz}$ ), respectively, with an increase in its corresponding excitation frequency. However, the addition of MWCNTs above the percolation threshold $(1.2 \mathrm{wt} \%)$ resulted in an reduction of the power density by $56.41 \%\left(2.33 \mu \mathrm{W} \mathrm{m}{ }^{-3}\right.$ at $31.57 \mathrm{~Hz}$ ). This effect can be attributed to the increased thermal resistivity for the flow of charge carriers within the matrix.

\subsection{Effect of MWCNTs on the performance of KNN composites}

3.4a Damping ratio: The effect of MWCNTs on the damping ratio, energy conversion and $K_{\mathrm{p}}$ parameters of KNN composite harvesters is shown in figure $9 \mathrm{a} . K_{\mathrm{p}}$ values were taken from author's previous research work [35]. The damping ratio of 0.055 for $\mathrm{KNN}$ ceramics decreased gradually with the addition of MWCNTs up to $0.9 \mathrm{wt} \%$ (0.0213) and 


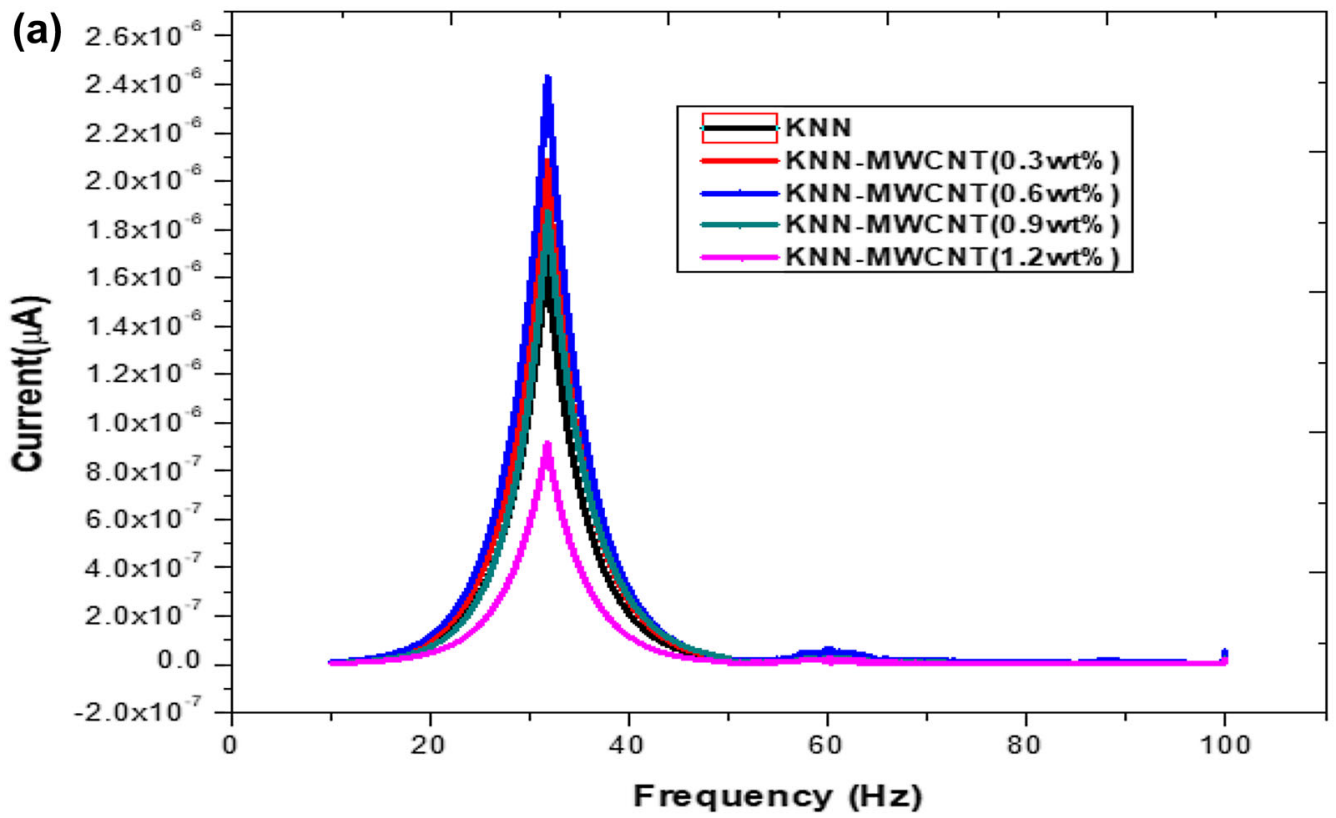

(b)

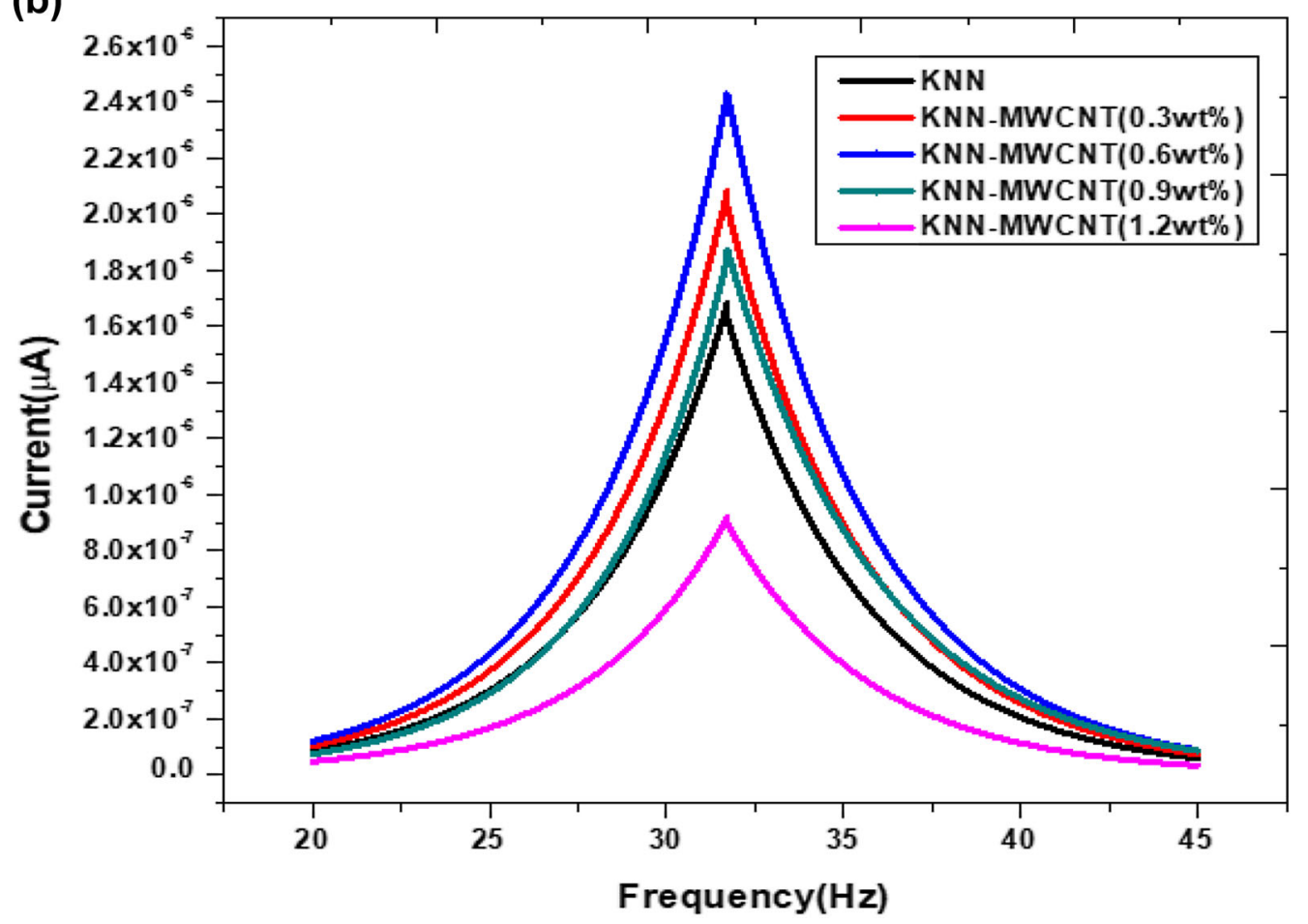

Figure 6. Current frequency responses of $\mathrm{KNN}$ and its composite-based harvesters (a) $0-100 \mathrm{~Hz}$ and (b) $20-45 \mathrm{~Hz}$ at an input acceleration of $0.5 \mathrm{~g}$.

increased for loading above the percolation threshold $(0.0378$ at $1.2 \mathrm{wt} \%$ ) as shown in figure 9a. The reduction in the damping ratio of KNN-MWCNT-based PEH can be attributed to the effect of MWCNTs on slippages of atoms at the interface and an increase in the damping ratio can be associated with improper distribution of MWCNTs across bulk grains of KNN composites. 3.4b Energy conversion: The effect of MWCNTs on the energy conversion factor of KNN composites is shown in figure 9a. The energy conversion of KNN ceramics increased gradually with the addition of MWCNTs into the matrix, reached a maximum of $0.9 \mathrm{wt} \%$ and reduced for loading of MWCNTs above the percolation threshold. The conversion value of the KNN ceramics being $24.07 \%$, increased to 


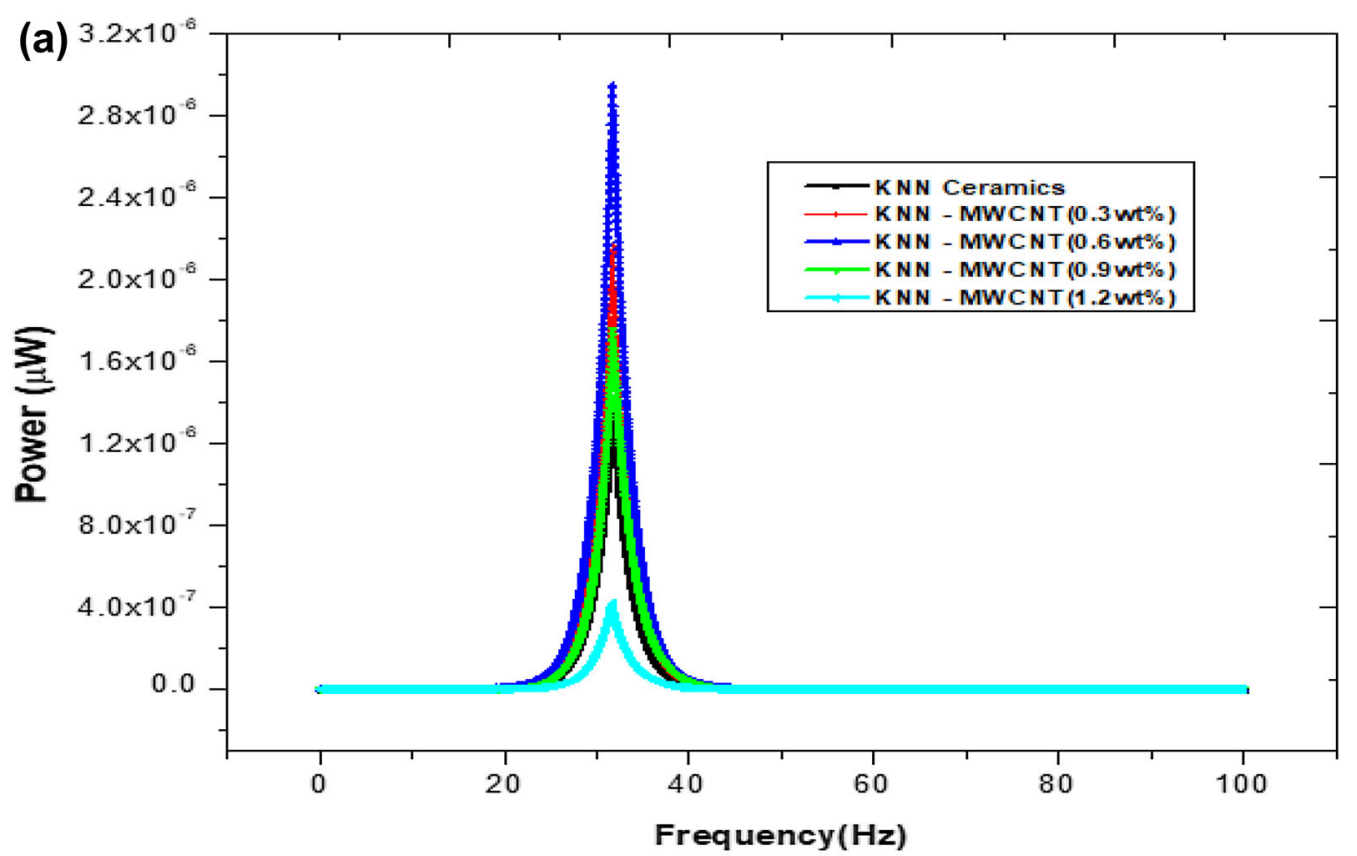

(b)

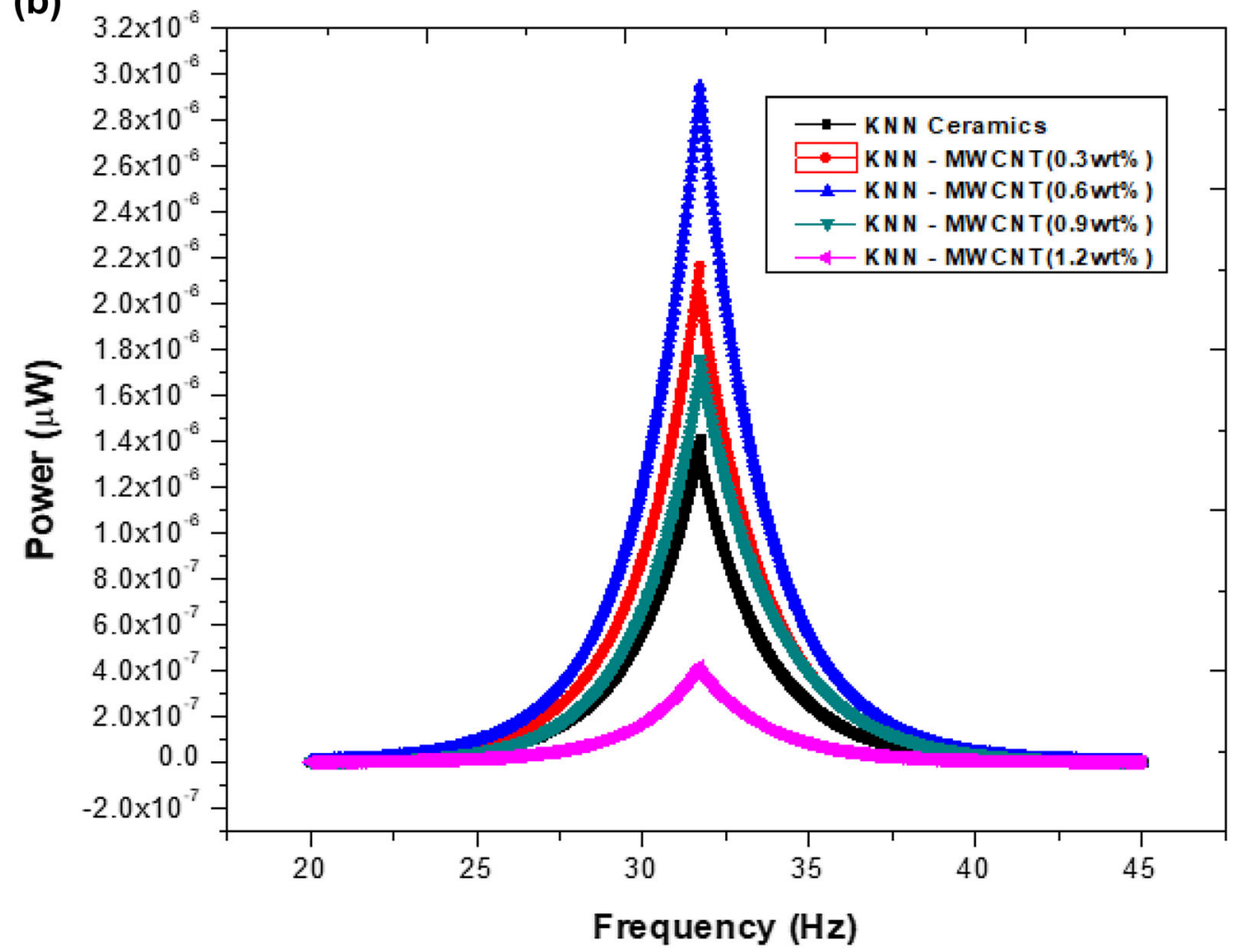

Figure 7. Power frequency response of $\mathrm{KNN}$ and its composite harvesters (a) $0-100 \mathrm{~Hz}$ and (b) $20-45 \mathrm{~Hz}$ at an input acceleration of $0.5 \mathrm{~g}$.

41.56\% MWCNT (0.3 wt \%), 63.39\% MWCNT (0.6 wt \%) and $100 \%$ MWCNT $(0.9 \mathrm{wt} \%)$ and decreased to $28.34 \%$ for $1.2 \mathrm{wt} \%$ loading of MWCNTs. The obtained maximum energy conversion factor of $100 \%$ can be attributed to the least damping effect $(0.0213(\xi))$ and high-coupling coefficient (0.46) achieved at $0.9 \mathrm{wt} \%$ as observed in figure $9 \mathrm{a}$.

3.4c Electromechanical coupling coefficients: The effect of MWCNTs on the electromechanical coupling coefficient 


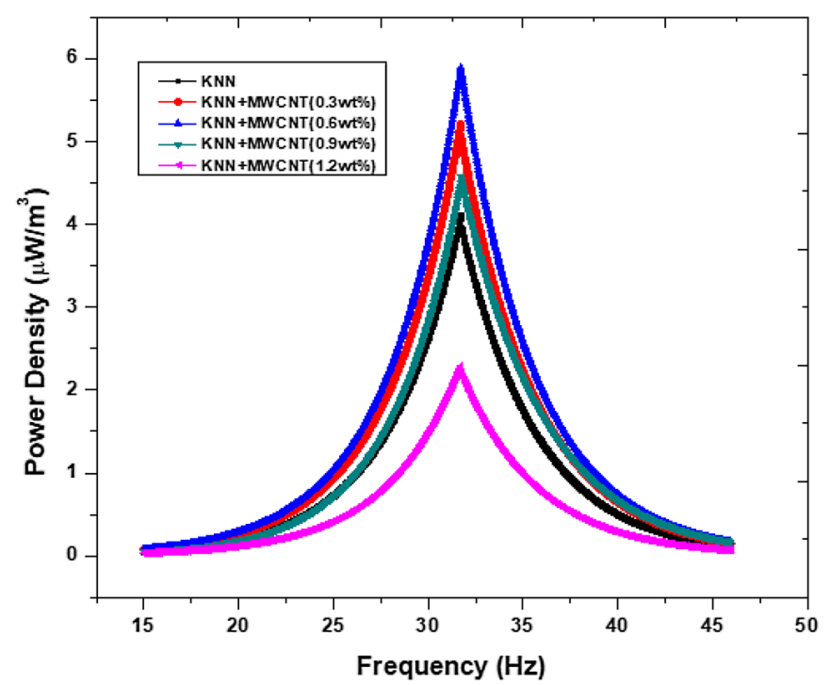

Figure 8. Harvested power density variation with frequency for different KNN composites.

of KNN composites is shown in figure 9a. The coupling coefficients of KNN ceramics increased with the addition of MWCNTs, reached a maximum at the threshold and reduced sharply for loading MWCNTs above the percolation threshold. KNN ceramics being 0.36 units increased by $8.79 \%(0.39$ at $0.3 \mathrm{wt} \%), 17.74 \%(0.42$ at $0.6 \mathrm{wt} \%)$ and $28.07 \%$ (0.46 at $0.9 \mathrm{wt} \%$ ), respectively. A further addition of MWCNTs above the percolation threshold resulted in the reduction by $11.11 \%$ ( 0.32 at $1.2 \mathrm{wt} \%)$, which can be associated with the increased damping effect and improper distribution of MWCNTs within the KNN matrix. However, the maximum coupling coefficient (0.46) obtained for KNN-MWCNT (0.9 wt\%) composites could be attributed to the strong electromechanical coupling coefficient achieved with the least damping effect.

3.4d Output performance: The variation of displacement, induced voltage and power output of KNN composites by addition of MWCNTs into the KNN matrix are shown in figure $9 \mathrm{~b}$. KNN ceramics are now observed with low-voltage potential $(1.67 \mathrm{~V})$, displacement $(1.23 \mathrm{~mm})$ and output power $(1.42 \mu \mathrm{W})$. It increased gradually with the addition of MWCNTs, reached the maximum at percolation threshold $(0.6 \mathrm{wt} \%)$ and reduced thereafter. A displacement of $1.23 \mathrm{~mm}$, as reported for $\mathrm{KNN}$ ceramics, increased gradually and reached a maximum of $1.78 \mathrm{~mm}$ for $0.6 \mathrm{wt} \%$ addition of MWCNTs. However, the addition of MWCNTs above threshold resulted in reduced displacement $(1.34 \mathrm{~mm}(0.9 \mathrm{wt} \%)$ and $0.47 \mathrm{~mm}(1.2 \mathrm{wt} \%))$ values due to the increased stiffness of the matrix. The voltage of $1.67 \mathrm{~V}$, being reported for KNN ceramics increased gradually and reached a maximum of $2.43 \mathrm{~V}$ at $0.6 \mathrm{wt} \%$ loading of MWCNTs due to the improved resistivity and strong electromechanical coupling system developed within the matrix as shown in figure $9 \mathrm{~b}$. However, there was a gradual reduction in the voltage potential developed $(1.87 \mathrm{~V}(0.9 \mathrm{wt} \%), 0.92 \mathrm{~V}$ $(1.2 \mathrm{wt} \%))$ by the composites for loading of MWCNTs above the percolation threshold. This effect can be attributed to the enhanced resistivity within the composite. Power of $\mathrm{KNN}$ ceramics being $1.42 \mu \mathrm{W}$ increased gradually with the addition of MWCNTs, reached a maximum of $2.95 \mu \mathrm{W}$ at percolation threshold $(0.6 \mathrm{wt} \%)$ and reduced drastically for loading MWCNTs above threshold $(1.76 \mu \mathrm{W}$ at $0.9 \mathrm{wt} \%$ and $0.419 \mu \mathrm{W}$ at $1.2 \mathrm{wt} \%$ ) as shown in figure $9 \mathrm{~b}$. This effect can be contributed to high-induced resistivity in the PEH of KNN-MWCNT composites.

3.4e Work done, power density and efficiency parameters: The effect of MWCNTs on work done, power density and efficiency parameters of KNN composites is shown in figure 10. The output parameters of $\mathrm{KNN}$ composites increased gradually with the addition of MWCNTs, reached maximum threshold $(0.6 \mathrm{wt} \%)$ and decreased drastically beyond percolation threshold. KNN ceramics observed with a power density of $3.47 \mu \mathrm{W} \mathrm{m}{ }^{-3}$ increased with the addition of MWCNTs by $56.48 \%\left(5.43 \mu \mathrm{W} \mathrm{m}{ }^{-3}\right.$ at $0.3 \mathrm{wt} \%), 88.15 \%\left(7.15 \mu \mathrm{W} \mathrm{m}^{-3}\right.$ at $\left.0.6 \mathrm{wt} \%\right)$ and $31.41 \%$ $\left(4.56 \mu \mathrm{W} \mathrm{m} \mathrm{m}^{-3}\right.$ at $\left.0.9 \mathrm{wt} \%\right)$ and decreased by $14.40 \%$ $\left(2.97 \mu \mathrm{W} \mathrm{m}^{-3}\right.$ at $\left.1.2 \mathrm{wt} \%\right)$. This effect can be attributed to a reduction in the volume of the KNN-MWCNT-based cantilever for loading of MWCNTs within the percolation range. Furthermore, KNN ceramics observed with an input power (work done) of $2.44 \mathrm{~J}$ increased with the addition of MWCNTs by $29.50 \%$ (3.16 J at $0.3 \mathrm{wt} \%$ ), $37.89 \%$ (3.52 J at $0.6 \mathrm{wt} \%)$ and $9.01 \%(2.66 \mathrm{~J}$ at $0.9 \mathrm{wt} \%)$ and decreased by $50.81 \%(1.20 \mathrm{~J}$ at $1.2 \mathrm{wt} \%)$ due to the reduced stiffness of the harvester. Finally, the efficiency of the KNN harvesters was found to be $58.15 \%$, increased with the addition of MWCNTs by $10 \%(0.3 \mathrm{wt} \%), 25.16 \%(0.6 \mathrm{wt} \%)$ and $7.93 \%$ $(0.9 \mathrm{wt} \%)$ and decreased by $23.7 \%(1.2 \mathrm{wt} \%)$ as shown in figure 10. This effect can be attributed to the structure, material, excitation and an electrical load resistance of $\mathrm{KNN}-$ MWCNT composites.

\section{4f Effect of MWCNTs on theoretical and measured output} power: A comparison between the theoretical and experimental power of $\mathrm{KNN}$ and its composites is depicted in figure 11. The measured and theoretical power of all the samples increased gradually, reached maximum at the threshold and reduced sharply. It can be attributed to the occurrence of percolation threshold for $0.6 \mathrm{wt} \%$ addition of MWCNTs into the matrix. The computed theoretical power was $1.43 \mu \mathrm{W}$ for KNN ceramics and it increased with the addition of MWCNTs by $45 \%(2.20 \mu \mathrm{W}$ at $0.3 \mathrm{wt} \%), 85 \%(3.08 \mu \mathrm{W}$ at $0.6 \mathrm{wt} \%)$ and $32 \%(1.89 \mu \mathrm{W}$ at $0.9 \mathrm{wt} \%)$ and decreased by $98 \%(0.45 \mu \mathrm{W}$ at $1.2 \mathrm{wt} \%)$ with the addition of reinforcement above threshold. The trend of the measured output power was mapped with that of the theoretical output power for KNN and its composites. The deviation being least (1.04\%) for KNN ceramics increased gradually with the addition of MWCNTs 


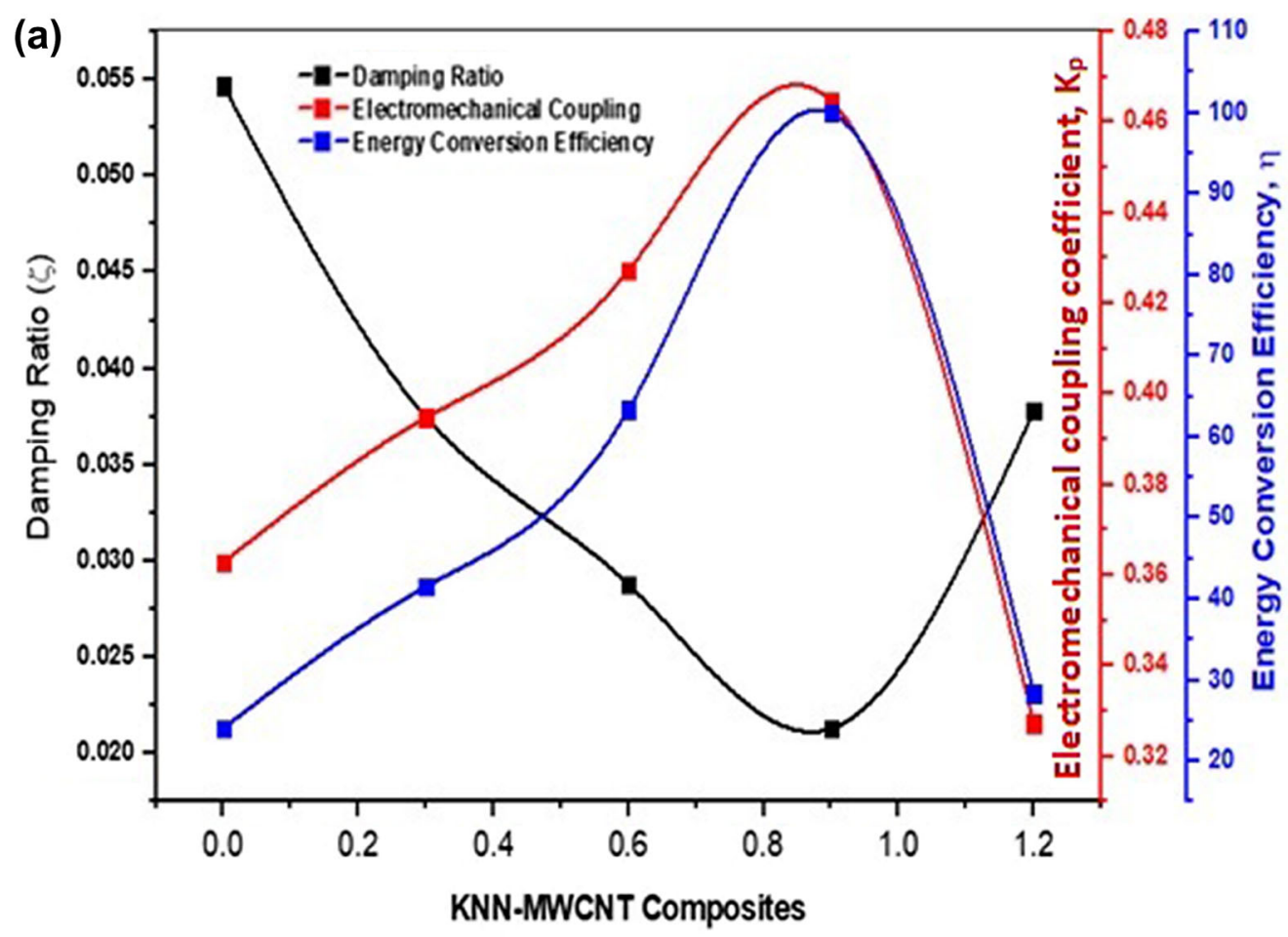

(b)

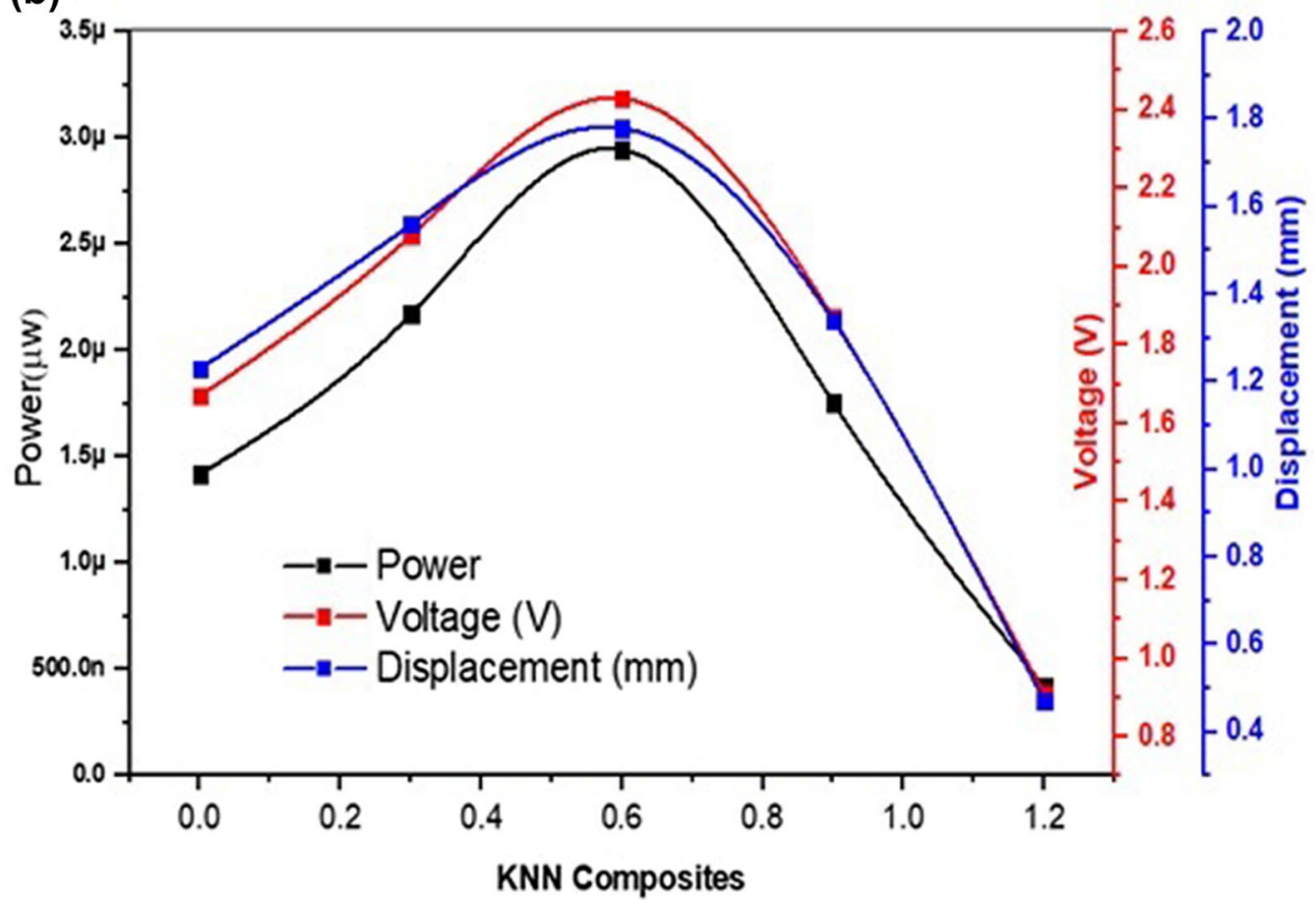

Figure 9. Effect of MWCNTs on (a) a damping ratio, electromechanical coupling coefficient, energy conversion and (b) voltage, displacement and power of KNN composites.

and was maximum $(7.34 \%)$ for loading reinforcement beyond percolation threshold. The deviations observed may be due to various errors, which come across right from synthesizing, developing and characterizing KNN composite harvesters due to their functional specifications.

\section{Discussion}

The performance of KNN-MWCNT composite energy harvesters varies with the percolation of electrostatic charges, damping effect, electromechanical coupling coefficients and 


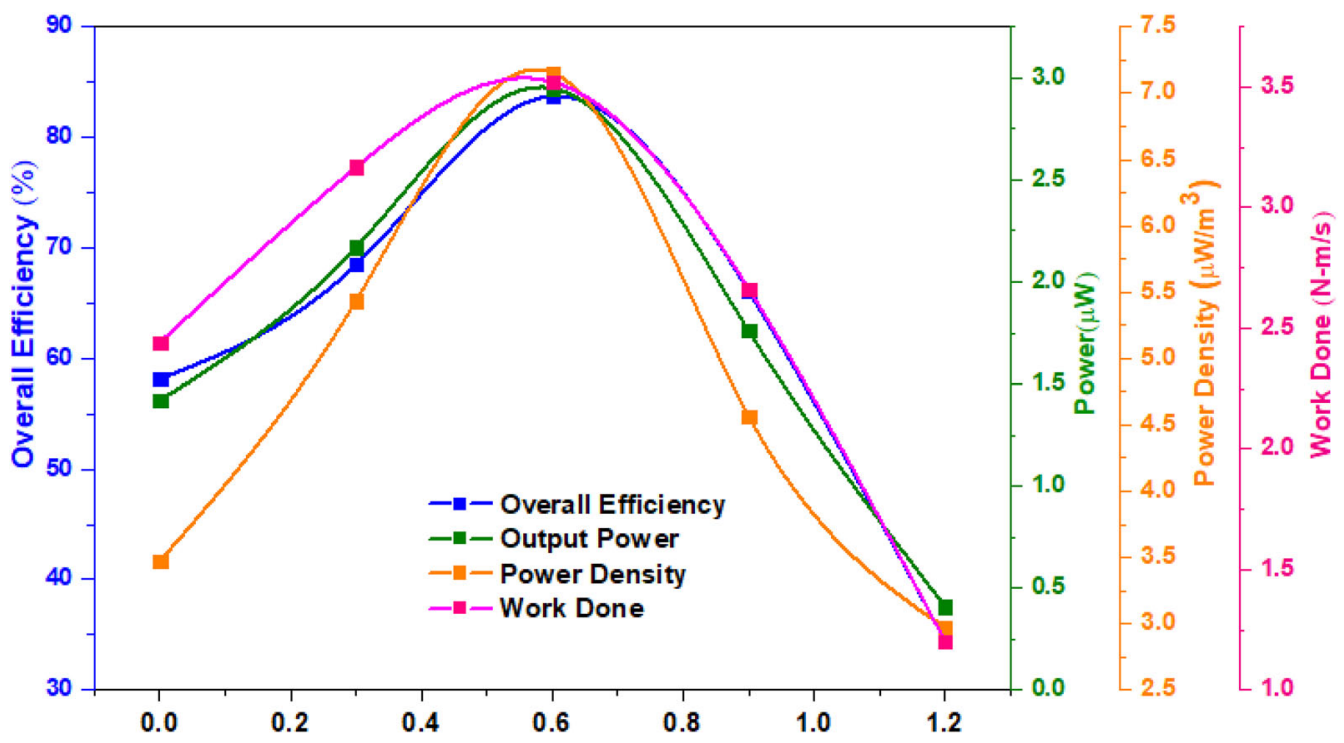

Figure 10. Effect of MWCNT on power, work done and efficiency of KNN composites.

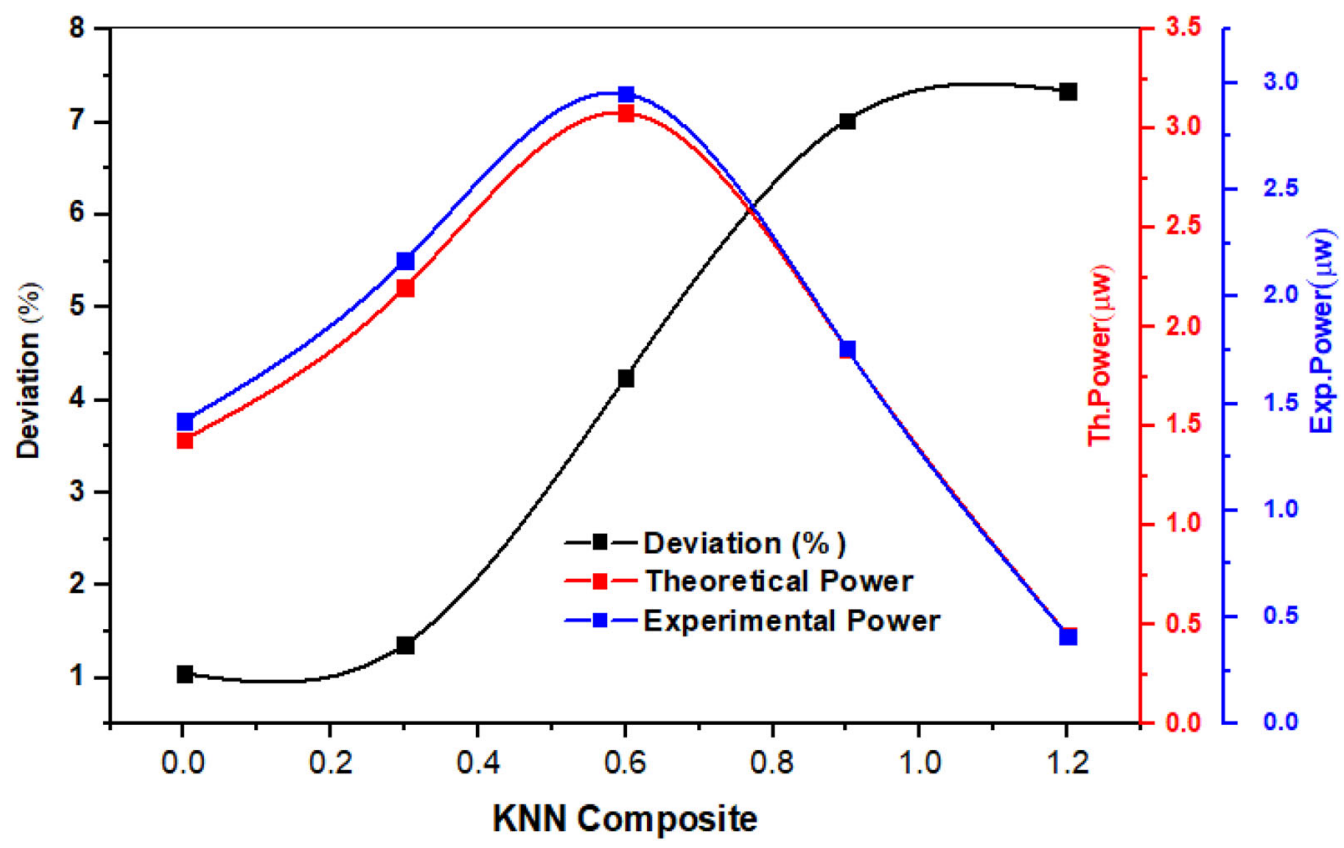

Figure 11. Effect of MWCNTs on theoretical/measured output parameters of KNN and its composites.

excitation frequency. The functional properties of $\mathrm{KNN}$ piezoelectric materials are satisfactory due to the existence of an energy band gap of $4.28 \mathrm{eV}$ [41]. Although the valence (+10) electrons in KNN ceramics result in enhancing the electrical conductivity by the flow of electrons, the charges are accumulated only at the surface (figure 12a). It percolates through the ceramics by drift and diffusion currents during polarization. This results in low-energy conversion and functional properties $\left(d_{33}, K_{\mathrm{P}}, \varepsilon_{\mathrm{r}}\right)$ [42]. From the sintered KNN ceramics, $2-3 \%$ porosity was observed from author's previous work [35]. The charges surrounding the pores were not percolated to the surface of the ceramics due to the lack of conductivity from the porous surface to outer surface during polarization. In the solid-state process, the solidification generally starts at the impurity or external particles or boundaries. The CNTs initiate the solidification at all stages, hence the CNTs sit in grain boundaries. It is because the solution of KNN and a known amount of MWCNTs were ultrasonicated, magnetically stirred separately and together for achieving uniform dispersion of MWCNTs into the KNN matrix. This 


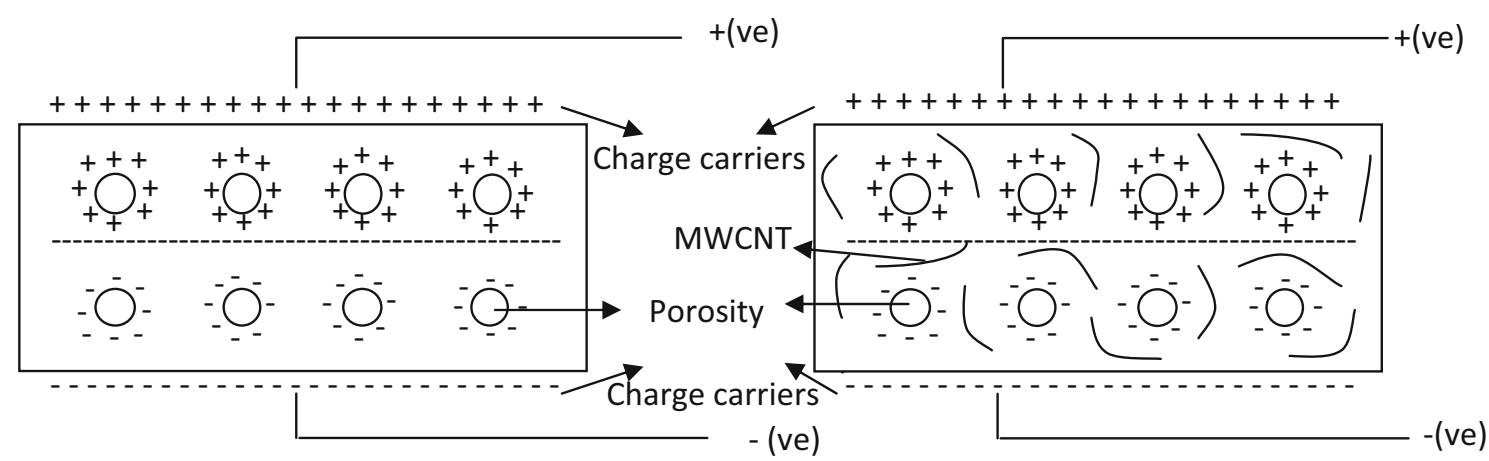

(a)

(b)

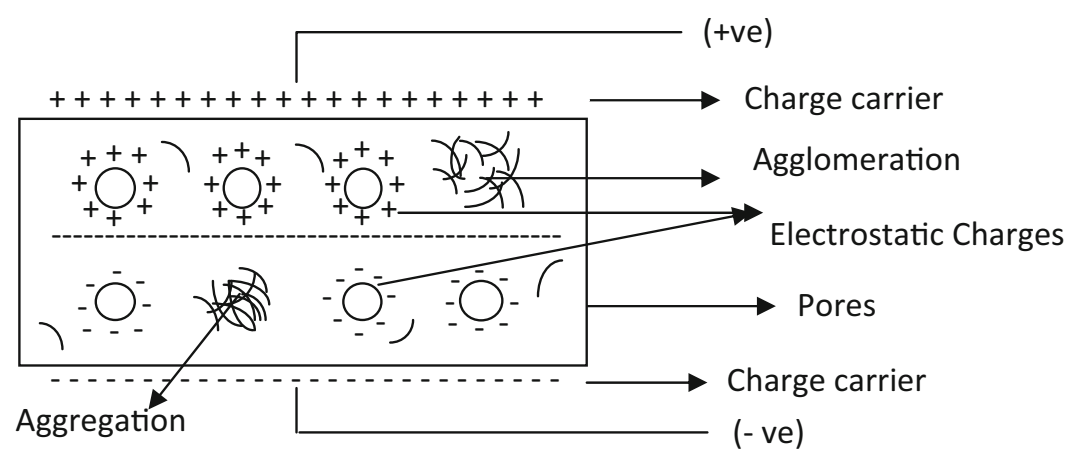

(c)

Figure 12. Schematic structure of poled (a) KNN ceramics, (b) KNN-MWCNT (0.3-0.9 wt\%) composites within threshold and (c) KNN composite (1.2 wt\%) above threshold.

was observed in the microstructure of densified KNN composites from our previous research work [35].

The addition of MWCNTs, which are isolated [43] near the grain boundary will interconnect effectively and form a conductive channel to transport the electrons to the surface, functioning like a ladder to cross the pores, cracks within the composite during polarization (figure 12b). It leads to an increased mobility of the charge carriers within the matrix, reduces the energy band gap due to structural modification [41], enhances the electrical properties and the voltage potential of KNN-MWCNT-based harvesters. The uniform dispersion of MWCNTs within the insulative KNN matrix results in fully dissipated electrical energy, strong piezo-damping effect $[34,44]$ and high-electrical energy conversion coefficient. The reduced resistivity within the matrix due to the addition of MWCNTs results in an increased frequency of oscillation, empowers the electric output and average power generated [45] by the KNN-MWCNT-based PEHUC.

The addition of MWCNTs into the matrix above percolation threshold (1.2 wt \%) resulted in agglomerations and aggregation of nanofillers [44], leading to the accumulation of charges in the form of clusters as shown in figure 12c. This change within the composite can be attributed to the sharp increase in conductivity due to the enhancement in the amount of localized-MWCNT percolation clusters, leading to drastic reduction in transportation of the charges to the surface due to the loss of connectivity between the porous and outer surface. This can be associated with the position of MWCNTs at bulk grain, which will not interconnect effectively to form the required conductive channel. As a result, energy does not get efficiently dissipated in the harvester and results in lower efficiency.

$\mathrm{KNN}$ ceramics possess lower interfacial bonding strength between the molecules. It leads to higher slippages at the interface, yields higher damping ratio and a lower mechanical quality factor. The lower mechanical $Q$ factor harvester experiences a smaller base motion amplitude and leads to lower energy conversion $[44,45]$. The addition of MWCNTs $(0.3-$ $0.9 \mathrm{wt} \%$ ) into the composite enhanced the interfacial bonding strength between the matrix and reinforcement, leading to increased stiffness, reduced mobility of the interfacial atoms and lower slippages between the molecules. This results in a lower damping ratio [46] and a higher $Q$ factor, which can be attributed to high-energy conversion [47]. However, the KNN-MWCNT (1.2 wt\%) composite shows lower stiffness and bonding strength of interfacial atoms due to uneven distribution (rare and dense) of nanofillers with lump mass aggregation. This resulted in an increased mobility of interfacial atoms, more slippages and higher damping ratio, leading to lower $Q$ factor and energy conversion.

The low-energy conversion rate of the KNN piezoelectric material leads to a weak electromechanical coupling 
coefficient due to the accumulation and conversion of charges only at the 2-D surfaces. In contrast, KNN-MWCNT (0.3-0.9 wt\%) composites show higher electrical energy conversion due to the accumulation and conversion of charges at 3-D spaces, as MWCNTs act like a ladder for carrying the charges from porous to the outer surface of the matrix. The high-conversion rate observed in KNN composites helps in improving the work done by the harvester due to the strong electromechanical system developed. However, in the case of KNN-MWCNT (1.2 wt\%) composites, the presence of lump masses of the reinforcement fails to utilize 3-D spaces and results in low percolation and connectivity within the matrix. Hence, it results in a low-energy conversion rate and weak coupling coefficient.

The lower natural frequency $(\sqrt{k / m})$ and higher damping ratio $\left(c / c_{\mathrm{c}}\right)$ of the $\mathrm{KNN}$ harvester are due to its higher density [35] and lower stiffness observed in KNN ceramics. It leads to a conversion of higher mechanical energy to thermal energy instead of electrical energy. Hence, the KNN harvester vibrates at a slower speed and results in lower base motion amplitude, induced voltage potential, output power and energy conversion coefficient. In the case of KNN-MWCNT (0.3-0.9 wt\%) composites, the addition of reinforcement resulted in reduced densities (4.34-4.30 $\mathrm{g} \mathrm{cc}^{-1}$ ) [35] and yielded in a high stiffness and low-damping ratio. So, KNN-MWCNT-based harvesters are getting excited at higher natural frequency and yields efficient conversion from mechanical energy to electrical energy with the minimum thermal loss. Hence, the KNN composite-based harvester results in higher base motion amplitude and enhances its output parameters. In addition, the KNN-MWCNT (1.2 wt\%) composite exhibits a lower density (4.19 $\mathrm{g} \mathrm{cc}^{-1}$ ) [35] and lower stiffness due to the agglomeration of MWCNTs. Under highly induced porosity, the harvester above threshold gets excited at low frequency and results in dissipation of more thermal energy. Hence, it yields a low-voltage potential, output power and conversion rate.

\section{Conclusion}

The effect of MWCNTs on the energy performance of KNNMWCNT composites was determined and the summary of the outcome of experimental results is given below:

1. The density of KNN composites decreases with increasing MWCNT reinforcement (up to $0.9 \mathrm{wt} \%$ ), hence higher the specific stiffness and frequency with a lower damping ratio.

2. The thermal stability of KNN composites up to a temperature of $200^{\circ} \mathrm{C}$ for $0.6 \mathrm{wt} \%$ addition of MWCNTs is due to their good binding strength between the matrix and reinforcement.
3. The optimal result obtained for KNN-MWCNT (0.6 wt\%) composite harvesters excelled with a least damping ratio (0.0288), high-electromechanical coupling factor (0.4273), energy conversion efficiency $(63.90 \%)$, output power density $(2.95 \mu \mathrm{W})$, power density $\left(7.15 \mu \mathrm{W} \mathrm{m}^{-3}\right)$ and maximum overall efficiency $(83.75 \%)$.

4. The experimentally obtained results are very close to the predicted theoretical output power of $\mathrm{KNN}_{-}$ MWCNT composites.

5. The KNN-MWCNT (0.6 wt\%)-based PEH is a potential candidate for energy harnessing and sensor applications.

\section{Acknowledgements}

The authors would like to acknowledge the financial support of R.V.C.E., Bangalore under TEQIP-II, Subcomponent 1.2, Characterization facilities support at CENSE Department under INUP, Material Engineering Department at IISC, Bangalore and technical guidance from Dr Rammohan Sriramdas, CENSE Dept., IISC, Bangalore.

\section{References}

[1] Shashank P 2007 J. Electroceram. 19167

[2] Kim H S, Kim J H and Kim J 2011 Int. J. Precis. Eng. Manuf. 12 1129

[3] Beeby S P, Tudor M J and White N M 2006 Meas. Sci. Technol. 17175

[4] Park S E and Shrout T R 1997 IEEE Trans. Ultrason. Ferroelectr. Freq. Control $\mathbf{4 4} 1140$

[5] Dubois M A and Muralt P 1999 Appl. Phys. Lett. 743032

[6] Wang X, Zhou J, Song J, Liu J, Xu N and Wang Z L 2006 Nano Lett. 62768

[7] Giurgiutiu V (ed) 2014 Structural health monitoring with piezoelectric wafer active sensors 2 nd edn (Cambridge, USA: Elsevier Academic Press) p 1024

[8] Uchino K 1998 Acta Mater. 463745

[9] Wang Q M, Zhang Q M, Xu B M, Liu R B and Cross L E 1999 J. Appl. Phys. 863352

[10] Chu S Y, Chen T Y, Tsai I T and Water W 2004 Sens. Actuators A Phys. $\mathbf{1 1 3} 198$

[11] Tang I T, Chen H J, Hwang W C, Wang Y C, Houng M P and Wang Y H 2004 J. Cryst. Growth 262461

[12] Koyama D and Nakamura K 2009 Ultrason. Symp. (IUS): IEEE Int. 1973

[13] Sodano H A, Inman D J and Park G 2004 Shock Vib. Dig. 36 197

[14] Swee-Leong K, Mohamad N, Weng Y D F, Kien C S and Fu D C 2011 Int. Conf. Electr. Control Comput. Eng. (INECCE) 12420

[15] Ng T H and Liao W J 2005 J. Intell. Mater. Syst. Struct. 16785

[16] Egerton L and Bieling C A 1938 Ceram. Bull. 471151

[17] Saito Y, Takao H, Tani T, Nonoyama T, Talkatori K, Homma T et al 2004 Nature $\mathbf{4 3 2} 84$ 
[18] Panda P K 2009 J. Mater. Sci. 445049

[19] Lam K H, Lin D M, Ni Y Q and Chan H L W 2009 Struct. Health Monit. 8283

[20] Guo M, Lam K H, Lin D M, Wang S, Kwok K W, Chan H L W et al 2007 J. Mater. Sci. 43709

[21] Kawada S, Kimura M, Higuchi Y and Takagi H 2009 Appl. Phys. Express 2111401

[22] Li E, Sasaki R, Hoshina T, Takeda H and Tsurumi T 2009 Jpn. J. Appl. Phys. 48 09KD11

[23] Zuo R and Ye C 2007 Appl. Phys. Lett. 91062916

[24] Saito Y and Takao H 2006 Ferroelectrics 33817

[25] Ming B Q 2007 J. Appl. Phys. 101054103

[26] Zuo R and Fu J 2011 J. Am. Ceram. Soc. 941467

[27] Xu W C, Lam K H, Choy S H and Chan H L W 2007 Integr. Ferroelectr. 8987

[28] Tanaka D, Tsukada T, Furukawa M, Wada S and Kuroiwa Y 2009 Jpn. J. Appl. Phys. 48 09KD08

[29] Zhang Q 2010 J. Alloys Compd. 490260

[30] Wu J, Xiao D, Wang Y, Wu W, Zhang B and Zhu J 2008 J. Phys. D.: Appl. Phys. 41125405

[31] Prince V, Ram Pratap P, Manmeeta and Dhiraj S 2016 AIP Conf. Proc. 1728020341

[32] Cristina E C, Padurarju L, Lavinia P C, Lupu N, Lisiecki I, Deluca M et al 2014 J. Appl. Phys. 116164110

[33] Ray M C and Bart R C 2007 Smart Mater. Struct. 161936
[34] Tian S, Cui F and Wang X 2008 Mater. Lett. 623859

[35] Nadar R N, Munishamaiah K, Suresh A V and Murthy H N 2018 Mater. Sci. Eng. B 23140

[36] Huang H, Zheng C, Ruan X, Zeng J, Zheng L, Chen W et al 2014 Ferroelectrics 4591

[37] Sriramdas R, Ramya C M, Kumar J S, Jain A and Rudra P 2014 J. ISSS 318

[38] Shu Y C and Lien I C 2006 J. Micromech. Microeng. 162429

[39] Renaud M, Karakaya K, Sterken T, Fiorini P, Hoof C V and Puers R 2008 Sens. Actuators A 380145

[40] Kanno I, Ichida T, Kotera H, Shibata K, Horikiri F and Mishima T 2011 Proc. Power MEMS 110

[41] Jyothi R, Kumar P P, Nidhi A N, Singh H, Yadav K L and Prakash S 2014 J. Mater. Sci. Technol. 30459

[42] Hong C H, Kim H P, Choi B Y, Han H S, Son J S, Ahn C W et al 2016 J. Materiomics 21

[43] Qing H and Gao L 2004 J. Mater. Chem. 162475

[44] Banerjee S, Cook Chennault K A, Du W, Sundar U, Halim H and Tang A 2016 Smart Mater. Struct. 25115018

[45] Elvin N and Erturk A 2013 in Advances in energy harvesting methods N Elvin and A Erturk (eds) (New York, NY: Springer) p 3445

[46] Her S C and Lai C Y 2013 Materials 62274

[47] Henry C, Fu K and Leang K 2012 IEEE Control Syst. Mag. 32 95 